\title{
Disruption of the glomerular basement membrane associated with nutcracker syndrome and double inferior vena cava in Noonan syndrome: a case report
}

Ayumi Omori ${ }^{1}$, Kan Katayama ${ }^{1 *} \mathbb{0}$, Ryosuke Saiki ${ }^{1}$, Satoru Masui ${ }^{2}$, Kei Suzuki ${ }^{3}$, Yoshinori Kanii ${ }^{4}$, Kayo Tsujimoto $^{1}$, Shiro Nakamori ${ }^{1}$, Tairo Kurita' ${ }^{1}$, Tomohiro Murata' ${ }^{1}$,Takahiro Inoue ${ }^{2}$ and Kaoru Dohi ${ }^{1}$

\begin{abstract}
Background: Nutcracker syndrome (NCS) is characterized by compression of the left renal vein (LRV) between the aorta and the superior mesenteric artery. While rare, NCS was reported to be accompanied by double inferior vena cava (IVC). We herein report a case of Noonan syndrome (NS) with double IVC who presented with macrohematuria and proteinuria.

Case presentation: The patient was a 23-year-old man, who had been diagnosed with NS due to RIT1 mutation, after showing foamy macrohematuria 3 weeks previously. A physical examination revealed low-set ears and a webbed neck. A urinalysis showed hematuria and proteinuria, and urinary sediments showed more than 100 isomorphic red blood cells per high-power field. His proteinuria and albuminuria concentrations were 7.1 and $4.5 \mathrm{~g} / \mathrm{g} \cdot \mathrm{Cr}$, respectively. Three-dimensional contrast-enhanced computed tomography (CT) showed double IVC and narrowing of the LRV after interflow of the left IVC. The aortomesenteric angle on a sagittal reconstruction of the CT image was $14.7^{\circ}$. Cystoscopy revealed a flow of macrohematuria from the left ureteral opening. On Doppler ultrasonography, there was scant evidence to raise the suspicion of the nutcracker phenomenon. Since severe albuminuria continued, a left kidney biopsy was performed. Light microscopy showed red blood cells in Bowman's space and the tubular lumen. Electron microscopy revealed disruption of the glomerular basement membrane (GBM). Vulnerability of the GBM was suspected and a genetic analysis revealed a heterozygous mutation at c.4793T> G (p.L1598R) in the COL4A3 gene. Screening for coagulation disorders revealed the factor VIII and von Willebrand factor (VWF) values were low, at 47.6 and 23\%, respectively. A multimer analysis of VWF showed a normal multimer pattern and he was diagnosed with von Willebrand disease type 1. As the bleeding tendency was mild, replacement of factor VIII was not performed. His macrohematuria and proteinuria improved gradually without treatment, and his urinalysis results have been normal for more than 6 months.
\end{abstract}

Conclusions: The present case showed macrohematuria and proteinuria due to NCS in NS with double IVC and von Willebrand disease type 1. The macrohematuria and proteinuria originated from glomerular hemorrhage because of vulnerability of the GBM due to COL4A3 mutation.

Keywords: Cystoscopy, COL4A3, Doppler ultrasonography, Hematuria, Proteinuria, von Willebrand

\footnotetext{
*Correspondence: katayamk@clin.medic.mie-u.ac.jp

${ }^{1}$ Department of Cardiology and Nephrology, Mie University Graduate

School of Medicine, 2-174 Edobashi, Tsu, Mie 514-8507, Japan

Full list of author information is available at the end of the article
}

(C) The Author(s) 2022. Open Access This article is licensed under a Creative Commons Attribution 4.0 International License, which permits use, sharing, adaptation, distribution and reproduction in any medium or format, as long as you give appropriate credit to the original author(s) and the source, provide a link to the Creative Commons licence, and indicate if changes were made. The images or other third party material in this article are included in the article's Creative Commons licence, unless indicated otherwise in a credit line to the material. If material is not included in the article's Creative Commons licence and your intended use is not permitted by statutory regulation or exceeds the permitted use, you will need to obtain permission directly from the copyright holder. To view a copy of this licence, visit http://creativecommons.org/licenses/by/4.0/. The Creative Commons Public Domain Dedication waiver (http://creativeco mmons.org/publicdomain/zero/1.0/) applies to the data made available in this article, unless otherwise stated in a credit line to the data. 


\section{Background}

Nutcracker syndrome (NCS) is characterized by compression of the left renal vein (LRV) between the aorta and the superior mesenteric artery [1]. An accurate diagnosis of NCS is sometimes difficult to make since a distended LRV can be observed as a normal anatomic variant [2]. Kim et al. proposed four different diagnostic criteria for NCS: the beak sign, the beak angle, the ratio of the LRV diameters, and angle between the superior mesenteric artery and the aorta [3]. Regarding the aortomesenteric angle on a sagittal reconstruction of computed tomography $(\mathrm{CT})$, the angle $<41^{\circ}$ was proposed for the definitive diagnosis [3].

The incidence of double inferior vena cava (IVC) is approximately $0.3-2.8 \%$ [4]. The left IVC usually terminates at the LRV, which passes anterior to the aorta to join the right IVC [5]. While rare, NCS was reported to be accompanied by left IVC or double IVC [6-9].

Noonan syndrome (NS) is an autosomal dominant disease caused by mutations in genes related to RAS/

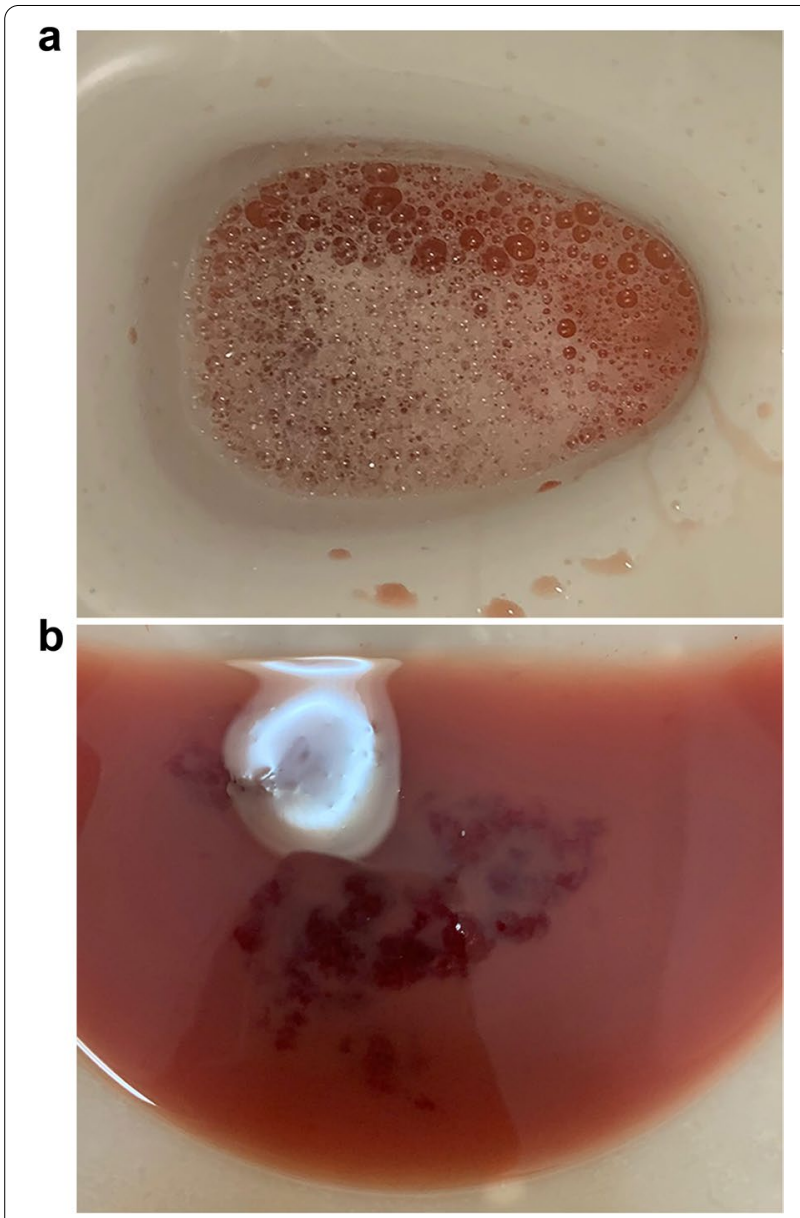

Fig. 1 (a) Foamy macrohematuria. (b) A chunk of blood was observed in the macrohematuria mitogen-activated protein kinase (MAPK) signaling pathway, such as PTPN11, SOS1, RAF1, KRAS, NRAS, $B R A F$, and RIT1 [10]. Approximately 79\% (153/194) of patients with NS were reported to have clotting factor deficiencies, von Willebrand disease, or platelet-related disorders [11].

Table 1 Laboratory data

\begin{tabular}{|c|c|c|c|}
\hline \multicolumn{2}{|l|}{ Urinary examination } & \multicolumn{2}{|l|}{ Blood chemistry } \\
\hline $\mathrm{pH}(4.5-7.5)$ & 7.5 & Glu (mg/dl, 73-109) & 80 \\
\hline Protein $(\mathrm{g} / \mathrm{g} \cdot \mathrm{Cr})$ & 7.1 & $\mathrm{TP}(\mathrm{g} / \mathrm{dl}, 6.6-8.1)$ & 6.7 \\
\hline Albumin $(\mathrm{g} / \mathrm{g} \cdot \mathrm{Cr})$ & 4.5 & Alb (g/dl, 4.1-5.1) & 4.6 \\
\hline Occult blood & $(3+)$ & BUN (mg/dl, 8-20) & 12.6 \\
\hline Glucose & $(-)$ & $\mathrm{Cr}(\mathrm{mg} / \mathrm{dl}, 0.65-1.07)$ & 0.65 \\
\hline$\beta_{2} M G(\mu g / l,<150)$ & 277 & $\mathrm{eGFR}\left(\mathrm{ml} / \mathrm{min} / 1.73 \mathrm{~m}^{2}\right)$ & 126.4 \\
\hline $\mathrm{NAG}(\mathrm{U} / \mathrm{g} \cdot \mathrm{Cr},<5.6)$ & 5.7 & UA (mg/dl, 3.7-7.8) & 4.2 \\
\hline \multirow[t]{2}{*}{$\mathrm{RBC}(/ \mathrm{HPF},<5)$} & $>100$ & $\mathrm{Na}(\mathrm{mEq} / \mathrm{l}, 138-145)$ & 141 \\
\hline & & $\mathrm{K}(\mathrm{mEq} / \mathrm{l}, 3.6-4.8)$ & 4.2 \\
\hline Complete blood count & & $\mathrm{Cl}(\mathrm{mEq} / \mathrm{l}, 101-108)$ & 106 \\
\hline WBC $(/ \mu \mathrm{l}, 3300-8600)$ & 4090 & $\mathrm{Ca}(\mathrm{mg} / \mathrm{dl}, 8.8-10.1)$ & 9.2 \\
\hline $\mathrm{RBC}\left(\times 10^{4} / \mu \mathrm{l}, 435-555\right)$ & 557 & $\mathrm{IP}(\mathrm{mg} / \mathrm{dl}, 2.7-4.6)$ & 3.1 \\
\hline $\mathrm{Hb}(\mathrm{g} / \mathrm{dl}, 13.7-16.8)$ & 16 & AST (U/I, 13-30) & 12 \\
\hline $\mathrm{Ht}(\%, 40.7-50.1)$ & 45.4 & $\operatorname{ALT}(U / I, 10-42)$ & 7 \\
\hline \multirow[t]{2}{*}{ Plt $\left(\times 10^{4} / \mu \mathrm{l}, 15.8-34.8\right)$} & 18 & LDH (U/I, 124-222) & 127 \\
\hline & & ALP (U/I, 38-113) & 67 \\
\hline Coagulation & & үGTP (U/I, 13-64) & 9 \\
\hline APTT (seconds, <37) & 37.2 & CRP (mg/dl, 0-0.14) & 0.02 \\
\hline PT (seconds, 9.8-12.1) & 11.8 & $\operatorname{lgG}(\mathrm{mg} / \mathrm{dl}, 861-1747)$ & 918 \\
\hline Fib (mg/dl, 200-400) & 197 & $\lg A(m g / d l, 93-393)$ & 125 \\
\hline Factor VIII (\%, 78-165) & 47.6 & $\operatorname{lgM}(\mathrm{mg} / \mathrm{dl}, 33-183)$ & 76 \\
\hline Factor IX (\%, 67-152) & 72.4 & C3 (mg/dl, 73-138) & 71 \\
\hline Factor XI (\%, 75-137) & 73.8 & $\mathrm{C} 4(\mathrm{mg} / \mathrm{dl}, 11-31)$ & 20.7 \\
\hline Factor XII (\%, 36-152) & 61.7 & CH50 (U/ml, 31.6-57.6) & 50.9 \\
\hline VWF $(\%, 50-150)$ & 23 & CEA (ng/ml, <5.2) & 1.1 \\
\hline \multirow[t]{2}{*}{ VWF antigen (\%) } & 37.3 & CA19-9 (U/ml, <36.8) & 8.5 \\
\hline & & PSA (ng/ml, <4) & 1.43 \\
\hline \multicolumn{4}{|l|}{ Serology } \\
\hline ANA $(<1: 40)$ & $<1: 40$ & & \\
\hline MPO-ANCA (U/ml, <3.5) & $<0.5$ & & \\
\hline PR3-ANCA (U/ml, <2.0) & $<0.5$ & & \\
\hline ASLO (IU/ml, <240) & $<13.6$ & & \\
\hline
\end{tabular}

Alb albumin; ALT alanine transaminase; ANA antinuclear antibody; APTT activated partial thromboplastin time; $A S L O$ antistreptolysin-O; AST asparate transaminase; $\beta_{2} M G \beta_{2}$-microglobulin; $B U N$ blood urea nitrogen; $C 3$ complement 3; $C 4$ complement 4; $\mathrm{Ca}$, calcium; $\mathrm{CH} 50,50 \%$ hemolytic complement activity; $\mathrm{Cl}$ chloride; $\mathrm{Cr}$ creatinine; CRP C-reactive protein; eGFR estimated glomerular filtration rate; Fib fibrinogen; Glu glucose; $\gamma G T P \gamma$-glutamyltranspeptidase; $\mathrm{Hb}$ hemoglobin; $\mathrm{Ht}$ hematocrit; IgA immunoglobulin A; I $g \mathrm{G}$ immunoglobulin $\mathrm{G}$; IgM immunoglobulin $M$; IP inorganic phosphate; $K$ kalium; $L D H$ lactate dehydrogenase; MPO-ANCA myeloperoxidase antineutrophil cytoplasmic antibody; Na natrium; NAG N-acetyl-B-D-glucosaminidase; Plt platelets; PSA prostate-specific antigen; PR3-ANCA serine proteinase3-anti-neutrophil cytoplasmic antibody; PT prothrombin time; $R B C$ red blood cells; TP total protein; $U A$ uric acid; $v W F$ von Willebrand factor; $W B C$ white blood cells 


\section{Case presentation}

A 23-year-old man, who had been diagnosed with NS due to a heterozygous variant at c.335G >C (p.G112A) in the RIT1 gene, developed foamy macrohematuria 3 weeks previously after driving for 6 h (Fig. 1a, b). He had no history of either left flank trauma or pain before the onset of the macrohematuria. A physical examination revealed low-set ears and a webbed neck, without mental retardation. Since he had received growth hormone replacement therapy, he did not have short stature; his height was $164.3 \mathrm{~cm}$, and his body weight was $56.1 \mathrm{~kg}$ (this had not changed recently). Mild pulmonary valve stenosis was followed up without any intervention.

His body temperature, pulse rate, and blood pressure on arrival were $36.6^{\circ} \mathrm{C}$, 59 beats/minute, and $113 / 56 \mathrm{mmHg}$, respectively. His laboratory data are

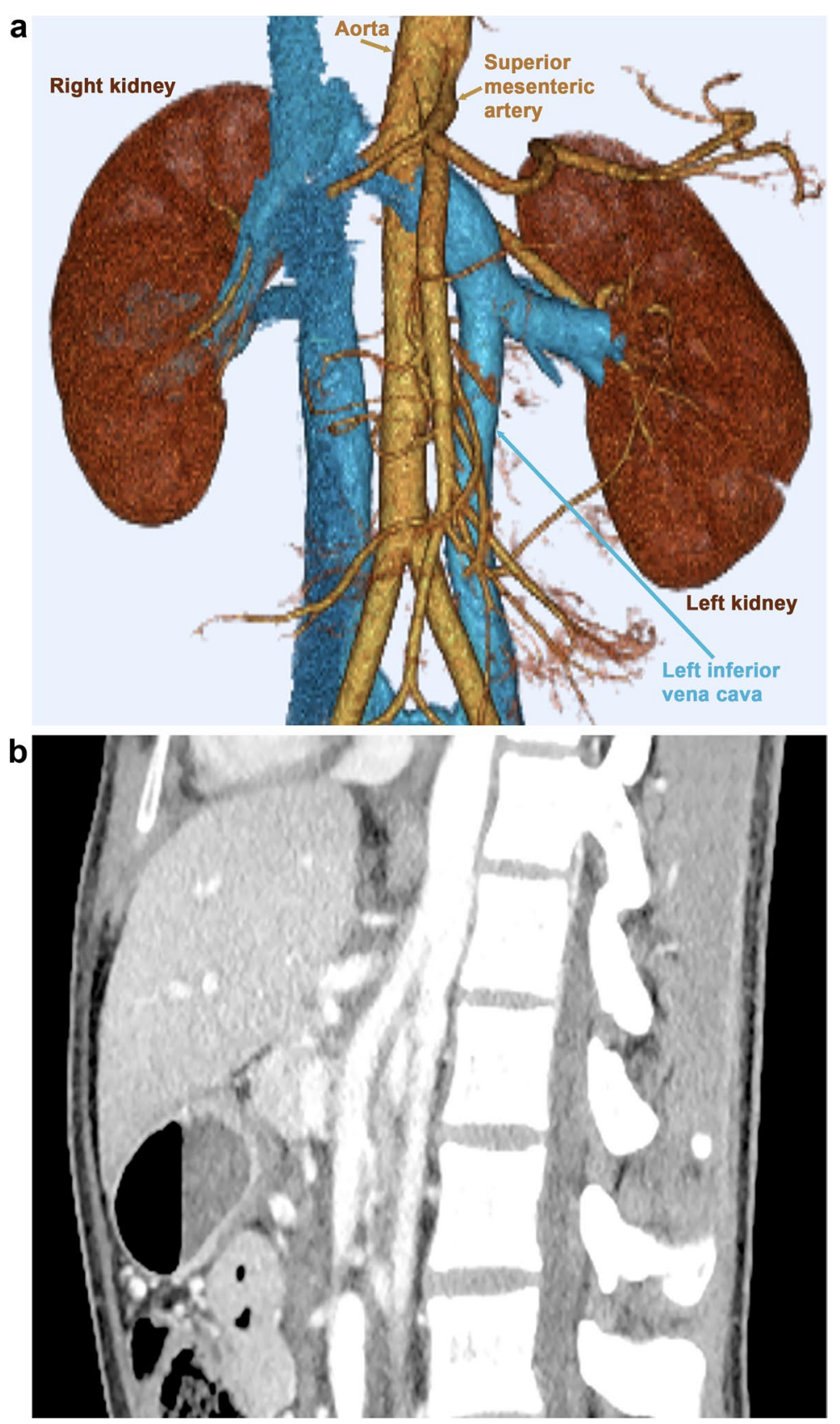

Fig. 2 (a) A three-dimensional contrast-enhanced computed tomography image. Double inferior vena cava and narrowing (arrowhead) of the left renal vein were observed after interflow of the left inferior vena cava. (b) The aortomesenteric angle on sagittal reconstruction of the computed tomography image was $14.7^{\circ}$ 
shown in Table 1. A urinalysis on arrival showed macrohematuria and proteinuria, and a urinary sediment analysis revealed more than 100 isomorphic red blood cells per high power field. The urinary protein creatinine ratio and albumin creatinine ratio were 7.1 and $4.5 \mathrm{~g} / \mathrm{g} \cdot \mathrm{Cr}$, respectively.

Three-dimensional contrast-enhanced CT showed double IVC and narrowing of the LRV after interflow of the left IVC (Fig. 2a, Supplementary Video S1). The aortomesenteric angle on sagittal reconstruction of the CT image was $14.7^{\circ}$ (Fig. 2b). Cystoscopy revealed a flow of macrohematuria from the left ureteral opening (Fig. 3a, b, Supplementary Video S2, and S3). Under the suspicion of NCS, Doppler ultrasonography was performed.

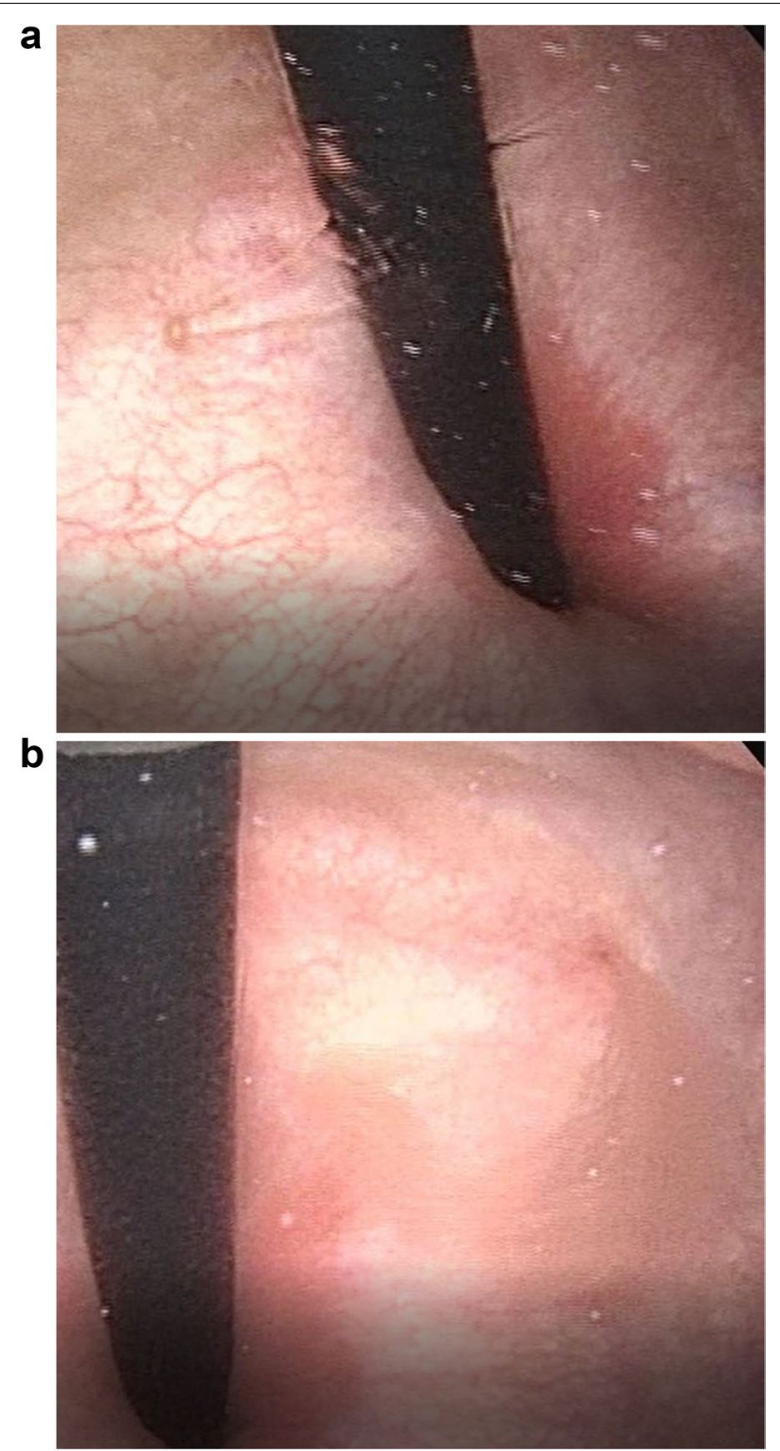

Fig. 3 (a) The flow of normal urine from the right ureteral opening. (b) The flow of macrohematuria from the left ureteral opening
The ratio of the LRV diameter at the hilar/aortomesenteric portion was $2.9(6.7 / 2.3 \mathrm{~mm})$ and the peak velocity at the aortomesenteric portion was $29 \mathrm{~cm} / \mathrm{s}$ with a pressure gradient of $0.33 \mathrm{mmHg}$; ultrasonography provided little evidence to raise the suspicion of the nutcracker phenomenon. On physical examination, no left varicoceles were apparent.

Since the severe albuminuria $(3.2 \mathrm{~g} / \mathrm{g} \cdot \mathrm{Cr})$ continued at 5 days after the initial presentation, he was admitted to our hospital to receive a left kidney biopsy. There were 18 glomeruli, which showed minor glomerular abnormalities. Light microscopy showed red blood cells in Bowman's space and the tubular lumen (Fig. 4a). An immunofluorescence study was negative for immunoglobulin G (IgG), IgA, IgM, complement 3 (C3), C1q, and fibrinogen. Electron microscopy revealed disruptions of the glomerular basement membrane (GBM) (Fig. 4b, Supplementary Fig. 1). He was discharged without any complications after kidney biopsy and was followed up as an outpatient. Doppler ultrasonography was repeated; however, the parameters did not show a major difference between the supine and upright position. His macrohematuria and proteinuria improved gradually without treatment. Although he experienced intermittent macrohematuria at home after discharge four times, neither proteinuria nor microhematuria were observed during follow-up examinations in the outpatient clinic at one, two, five, eight and 14 months after discharge.

As vulnerability of the GBM was suspected based on electron microscopy, genetic analyses of COL4A3 and COL4A4 were performed, which revealed a heterozygous variant at c.4793 T > G (p.L1598R) in the COL4A3 gene (Fig. 4c). Screening for coagulation disorders revealed that the patient's factor VIII and von Willebrand factor (vWF) values were low at 47.6 and $23 \%$, respectively. A multimer analysis of vWF showed a normal multimer pattern and he was diagnosed with von Willebrand disease type 1 . As the bleeding tendency was mild, replacement of factor VIII was not performed.

\section{Discussion and conclusions}

We experienced a case with macrohematuria and proteinuria. Although repeated Doppler ultrasonography did not show evidence of NCS, the aortomesenteric angle on sagittal reconstruction of the CT image was $14.7^{\circ}$, which fulfilled the criterion of $<35^{\circ}$ for the diagnosis of NCS [1]. The present case also had double IVC, which might have predisposed the patient to NCS, as was described in a previous report [9]. As macrohematuria in NCS was explained by rupture of the thin-walled varices due to LRV hypertension [12], severe albuminuria was thought to be unusual in the present case and the left kidney biopsy was performed. Light microscopy confirmed the 


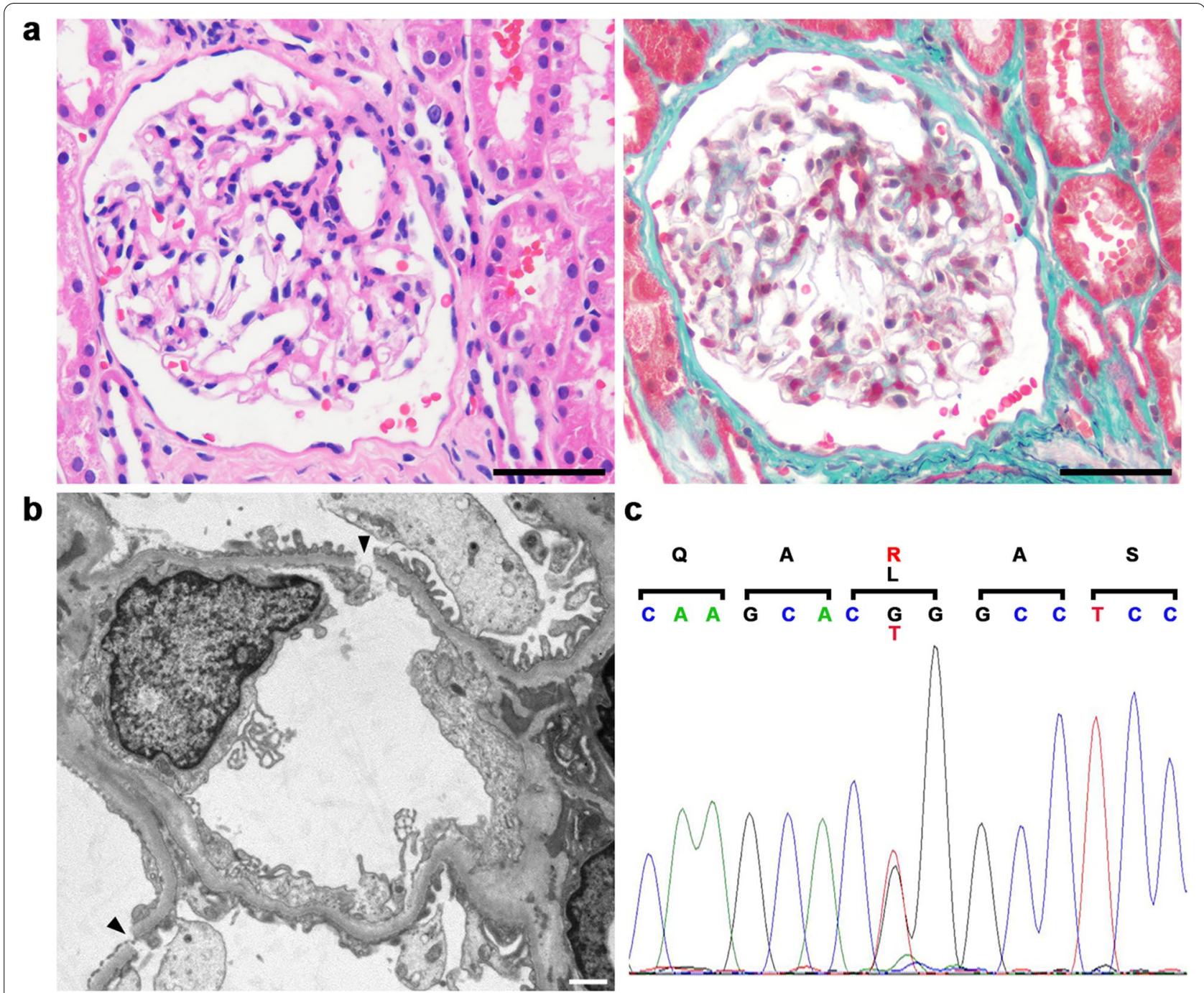

Fig. 4 (a) Light microscopy showed red blood cells in Bowman's space and the tubular lumen with hematoxylin and eosin staining (left panel) and Masson trichrome staining (right panel). Bars $=50 \mu \mathrm{m}$. (b) Transmission electron microscopy showed glomerular basement membrane disruption (arrowheads). Bar $=1 \mu \mathrm{m}$. (c) A genetic analysis revealed a heterozygous variant at c.4793T>G (p.L1598R) in the COL4A3 gene

presence of red blood cells in both Bowman's space and the tubular lumen and disruption of the GBM was confirmed by electron microscopy, suggesting that the macrohematuria and proteinuria originated from glomerular hemorrhage. The isomorphic hematuria in the present case might represent the severity of the disruption of the GBM, since glomerular hemorrhage usually appears as dysmorphic hematuria. A previous case in a single kidney showed nephrotic range proteinuria due to NCS; however, a kidney biopsy was not performed, and the origin of the proteinuria was unknown [13].

In the present case, a genetic analysis was performed to investigate the origin of the vulnerability of the GBM and a heterozygous variant was identified at c.4793 T > G
(p.L1598R) in the COL4A3 gene. A previous report showed that a patient with $\mathrm{c} .4793 \mathrm{~T}>\mathrm{G}$ in COL4A3 and c.448G $>\mathrm{C}$ in $C O L 4 A 5$ had irregular thinning of the GBM while his father with c.4793 T > G in COL4A3 did not show hematuria [14]. Another previous report analyzed 24 patients with autosomal recessive Alport syndrome, 17 of which had mutations in COL4A3 [15]. Of the 17 patients, 13 had compound heterozygous mutations in COL4A3, 5 of which had c.4793 T $>\mathrm{G}$ in $C O L 4 A 3$. Among the parents of the 5 patients, only one mother with c.4793 $\mathrm{T}>\mathrm{G}$ in $C O L 4 A 3$ had hematuria; the other parents seemed normal [14]. As the thinness of the GBM in the present case was not obvious and hematuria had not been pointed out previously, c.4793 T > G 


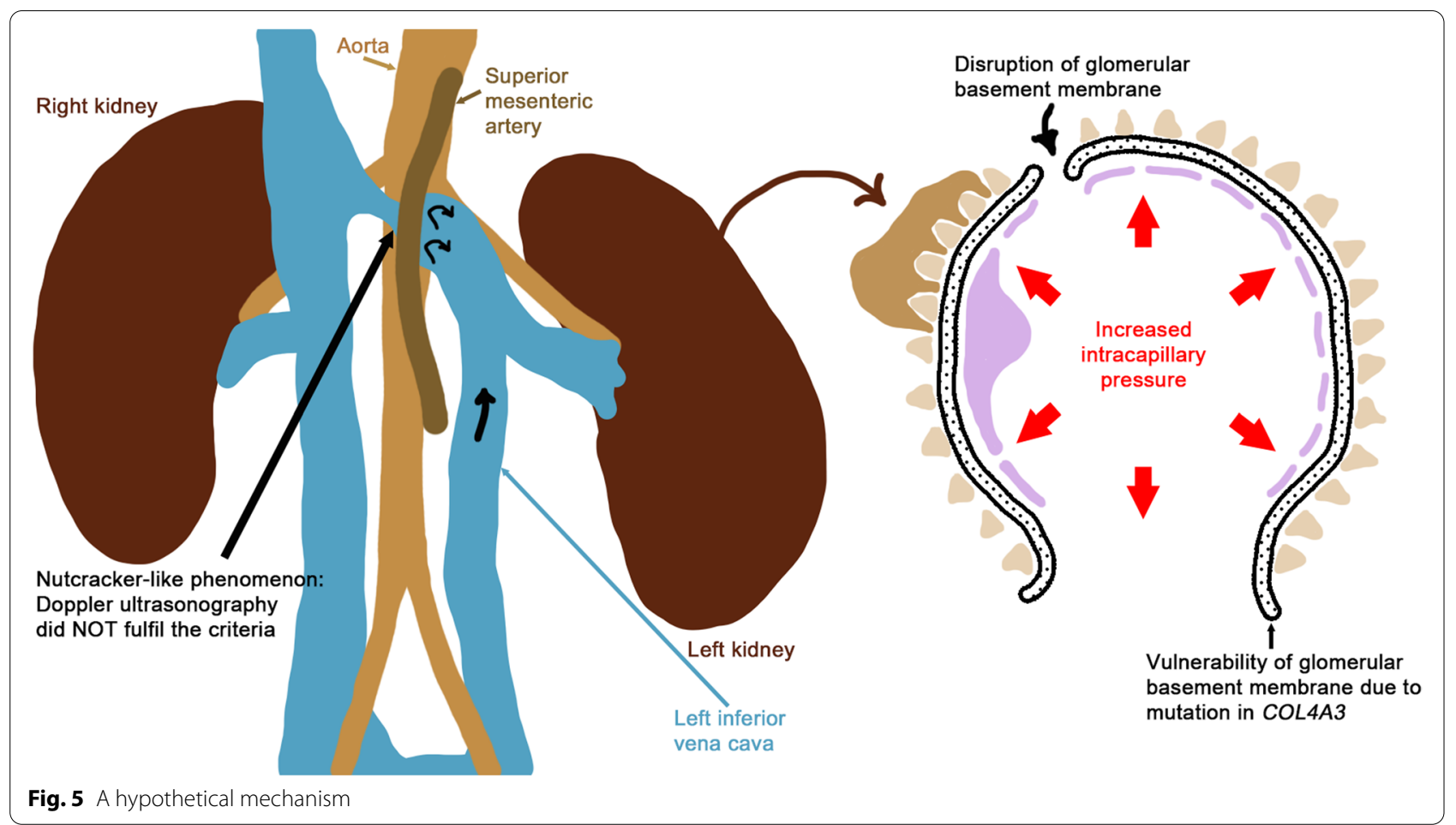

in COL4A3 might not have affected the synthesis of the triple helical molecule of the type IV collagen $\alpha 3 / 4 / 5$ chains. However, the disruption of the GBM in the present case implied that p.L1598R in the carboxy-terminal non-collagenous 1 (NC1) domain of the type IV collagen $\alpha 3$ chain may affect the associative strength between the type IV collagen triple helical molecules. The spontaneous remission of proteinuria in the present case might imply that the disruption of the GBM was repaired by newly synthesized collagen molecules after the end of the long drive. The hypothetical mechanism of the present case is shown in Fig. 5.

The patient in the present case had been diagnosed with NS due to RIT1 mutation. While there is a case report of a patient with nephrotic syndrome due to crossed fused ectopic kidneys in NS [16], nephrotic range proteinuria in NS is rare. Coagulation defects were reported in $31 \%(4 / 13)$ of NS patients with RIT1 mutations [17]. The present case had low factor VIII and vWF activity with a normal multimer pattern, which was compatible with von Willebrand disease type 1. Although the coagulation disorders in the present case might have partially affected the onset of NCS, macrohematuria spontaneously improved in the present case and his von Willebrand disease type 1 was thought to be mild since the vWF antigen value was $37.3 \%$.
In conclusion, the present case showed macrohematuria and proteinuria due to NCS in NS with double IVC and von Willebrand disease type 1 , and the origin of the macrohematuria and proteinuria came from glomerular hemorrhage because of vulnerability of the GBM due to COLAA3 mutation.

\section{Abbreviations}

C3: Complement 3; CT: Computed tomography; GBM: Glomerular basement membrane; IgG: Immunoglobulin G; IVC: Inferior vena cava; LRV: Left renal vein; MAPK: Mitogen-activated protein kinase; NC1: Non-collagenous 1; NCS: Nutcracker syndrome; NS: Noonan syndrome; vWF: Von Willebrand factor.

\section{Supplementary Information}

The online version contains supplementary material available at https://doi. org/10.1186/s12882-022-02671-4.

Additional file 1: Supplementary Video S1. A 3D reconstruction of the entire left IVC subsystem.

Additional file 2: Supplementary Video S2. The flow of normal urine from the right ureteral opening.

Additional file 3: Supplementary Video S3. The flow of macrohematuria from the left ureteral opening.

Additional file 4: Supplementary Fig. S1. Transmission electron microscopy

Acknowledgements Not applicable. 


\section{Authors' contributions}

$\mathrm{AO}, \mathrm{KK}, \mathrm{RS}, \mathrm{SM}, \mathrm{KS}$, YK and KT participated in the acquisition of clinical data. AO, KK, RS, SN, TK, and TM carried out analysis of patient's clinical course and data interpretation. $\mathrm{AO}$ and $\mathrm{KK}$ wrote a draft of the manuscript and RS, SM, KS, YK, $K T, S N, T K, T M, T I$, and KD revised it critically. All authors read and approved the final manuscript.

\section{Funding}

Not applicable.

\section{Availability of data and materials}

The datasets used and/or analyzed during the current study are available from the corresponding author on reasonable request.

\section{Declarations}

Ethics approval and consent to participate

Not applicable.

\section{Consent for publication}

Written informed consent was obtained from the patient for the publication of this case report. A copy of the written consent is available for review by the editor of this journal.

\section{Competing interests}

The authors declare no competing interests in association with the present study.

\section{Author details}

'Department of Cardiology and Nephrology, Mie University Graduate School of Medicine, 2-174 Edobashi, Tsu, Mie 514-8507, Japan. ${ }^{2}$ Department of Nephro-Urologic Surgery and Andrology, Mie University Graduate School of Medicine, Tsu, Japan. ${ }^{3}$ Department of Hematology and Oncology, Mie University Graduate School of Medicine, Tsu, Japan. ${ }^{4}$ Department of Radiology, Mie University Hospital, Tsu, Japan,

Received: 4 November 2021 Accepted: 15 January 2022

Published online: 12 February 2022

\section{References}

1. Ananthan K, Onida S, Davies AH. Nutcracker syndrome: an update on current diagnostic criteria and management guidelines. Eur J Vasc Endovasc Surg. 2017;53(6):886-94.

2. Buschi AJ, Harrison RB, Norman A, Brenbridge AG, Williamson BR, Gentry $\mathrm{RR}$, et al. Distended left renal vein: $\mathrm{CT} /$ sonographic normal variant. AJR Am J Roentgenol. 1980;135(2):339-42.

3. Kim KW, Cho JY, Kim SH, Yoon JH, Kim DS, Chung JW, et al. Diagnostic value of computed tomographic findings of nutcracker syndrome: correlation with renal venography and renocaval pressure gradients. Eur J Radiol. 2011;80(3):648-54.

4. Mayo J, Gray R, St Louis E, Grosman H, McLoughlin M, Wise D. Anomalies of the inferior vena cava. AJR Am J Roentgenol. 1983;140(2):339-45.

5. Bass JE, Redwine MD, Kramer LA, Huynh PT, Harris JH Jr. Spectrum of congenital anomalies of the inferior vena cava: cross-sectional imaging findings. Radiographics. 2000;20(3):639-52

6. Gupta A, Naik N, Gulati GS. Mesoaortic entrapment of a left inferior vena cava. Indian J Radiol Imaging. 2010;20(1):63-5.

7. Pulgarin Ricardo LG, Isaza Zapata S, Uribe GR. Left inferior vena cava with nutcracker syndrome: a case report. Radiol Case Rep. 2017;13(1):32-4.

8. Ueda Y, Aoyagi H, Okamoto T. Left-sided inferior vena cava with nutcracker syndrome. Clin Exp Nephrol. 2019;23(3):425-6.

9. Waśniewska A, Ruzik K, Olewnik Ł, Stefańczyk L, Polguj M. Unusual coexistence of double inferior vena cava with nutcracker syndrome-a case report and review of the literature. J Int Med Res. 2020;48(2):300060520904520.
10. Shoji Y, Ida S, Niihori T, Aoki Y, Okamoto N, Etani Y, et al. Genotype-phenotype correlation analysis in Japanese patients with Noonan syndrome. Endocr J. 2019;66(11):983-94.

11. Nugent DJ, Romano AA, Sabharwal S, Cooper DL. Evaluation of bleeding disorders in patients with Noonan syndrome: a systematic review. J Blood Med. 2018;23(9):185-92.

12. Little AF, Lavoipierre AM. Unusual clinical manifestations of the nutcracker syndrome. Australas Radiol. 2002;46(2):197-200.

13. Ozçakar ZB, Yalçınkaya F, Fitöz S, Cipe G, Soygür T, Ozdemir H, et al. Nutcracker syndrome manifesting with severe proteinuria: a challenging scenario in a single-kidney patient. Pediatr Nephrol. 2011;26(6):987-90.

14. Zhang L, Sun BC, Zhao BG, Ma QS. An overview of the multi-pronged approach in the diagnosis of Alport syndrome for 22 children in Northeast China. BMC Nephrol. 2020;21(1):294.

15. Oka M, Nozu K, Kaito H, Fu XJ, Nakanishi K, Hashimura Y, et al. Natural history of genetically proven autosomal recessive Alport syndrome. Pediatr Nephrol. 2014;29(9):1535-44.

16. Gupta A, Khaira A, Lal C, Mahajan S, Tiwari SC. Noonan syndrome: crossed fused ectopic kidneys and focal segmental glomerulosclerosis-a rare association. Clin Exp Nephrol. 2009;13(5):531-2.

17. Yaoita M, Niihori T, Mizuno S, Okamoto N, Hayashi S, Watanabe A, et al. Spectrum of mutations and genotype-phenotype analysis in Noonan syndrome patients with RIT1 mutations. Hum Genet. 2016;135(2):209-22.

\section{Publisher's Note}

Springer Nature remains neutral with regard to jurisdictional claims in published maps and institutional affiliations.
Ready to submit your research? Choose BMC and benefit from:

- fast, convenient online submission

- thorough peer review by experienced researchers in your field

- rapid publication on acceptance

- support for research data, including large and complex data types

- gold Open Access which fosters wider collaboration and increased citations

- maximum visibility for your research: over $100 \mathrm{M}$ website views per year

At BMC, research is always in progress.

Learn more biomedcentral.com/submissions 